\title{
Removal of Protein-Bound Uremic Toxins Using Binding Competitors in Hemodialysis: A Narrative Review
}

\author{
Vaibhav Maheshwari ${ }^{1, *}$, Xia Tao ${ }^{1}$, Stephan Thijssen ${ }^{1}$ and Peter Kotanko ${ }^{1,2}$ \\ 1 Renal Research Institute, New York, NY 10065, USA; Xia.Tao@rriny.com (X.T.); \\ Stephan.Thijssen@rriny.com (S.T.); Peter.Kotanko@rriny.com (P.K.) \\ 2 Icahn School of Medicine at Mount Sinai, New York, NY 10029, USA \\ * Correspondence: Vaibhav.Maheshwari@rriny.com
}

Citation: Maheshwari, V.; Tao, X.; Thijssen, S.; Kotanko, P. Removal of Protein-Bound Uremic Toxins Using Binding Competitors in Hemodialysis: A Narrative Review. Toxins 2021, 13, 622. https://doi.org/10.3390/ toxins 13090622

Received: 9 August 2021

Accepted: 31 August 2021

Published: 4 September 2021

Publisher's Note: MDPI stays neutral with regard to jurisdictional claims in published maps and institutional affiliations.

Copyright: (C) 2021 by the authors. Licensee MDPI, Basel, Switzerland. This article is an open access article distributed under the terms and conditions of the Creative Commons Attribution (CC BY) license (https:/ / creativecommons.org/licenses/by/ $4.0 /)$.

\begin{abstract}
Removal of protein-bound uremic toxins (PBUTs) during conventional dialysis is insufficient. PBUTs are associated with comorbidities and mortality in dialysis patients. Albumin is the primary carrier for PBUTs and only a small free fraction of PBUTs are dialyzable. In the past, we proposed a novel method where a binding competitor is infused upstream of a dialyzer into an extracorporeal circuit. The competitor competes with PBUTs for their binding sites on albumin and increases the free PBUT fraction. Essentially, binding competitor-augmented hemodialysis is a reactive membrane separation technique and is a paradigm shift from conventional dialysis therapies. The proposed method has been tested in silico, ex vivo, and in vivo, and has proven to be very effective in all scenarios. In an ex vivo study and a proof-of-concept clinical study with 18 patients, ibuprofen was used as a binding competitor; however, chronic ibuprofen infusion may affect residual kidney function. Binding competition with free fatty acids significantly improved PBUT removal in pre-clinical rat models. Based on in silico analysis, tryptophan can also be used as a binding competitor; importantly, fatty acids or tryptophan may have salutary effects in HD patients. More chemoinformatics research, pre-clinical, and clinical studies are required to identify ideal binding competitors before routine clinical use.
\end{abstract}

Keywords: binding competition; hemodialysis; intoxication; indoxyl sulfate; p-cresyl sulfate; CMPF

Key Contribution: This review provides a comprehensive summary of current evidence in support of binding competition as a potential method to improve protein-bound uremic toxin removal during hemodialysis.

\section{Introduction}

Uremic toxins have broadly been classified into three categories: (1) small-sized toxins (<500 Da), (2) middle and large-sized uremic toxins (>500 Da), and (3) protein-bound uremic toxins (PBUTs) [1]. In an updated definition, these solutes were further classified based on their origins, molecule weight, and albumin-binding properties [2]. In end-stage kidney disease (ESKD) patients, these toxins accumulate, and patients must undergo dialysis to reduce the levels of these toxins. Conventional hemodialysis (three times a week, four hours per session) provides adequate removal of small, non-protein-bound solutes such as urea and creatinine. Removal of middle-sized toxins such as $\beta_{2}$-microgloblin is also improved by convection-based hemodiafiltration (HDF). However, removal of PBUTs is particularly poor during conventional hemodialysis (HD) [3], and HDF provides only marginal improvement over HD $[4,5]$. PBUT removal in the extracorporeal renal replacement therapies is poor because the majority of PBUTs are tightly bound to protein, with albumin being the primary carrier protein, and only a small free fraction is available for transfer across the dialyzer membrane [6]. The lower free toxin concentration results in a smaller diffusive gradient for toxin removal in dialysis, while convection is not helpful due to membrane size cut-off to retain proteins and, hence, albumin-bound toxins. 
For the prototypical PBUTs indoxyl sulfate (IS) and p-cresyl sulfate (pCS), with known toxicities in chronic kidney disease patients [2,7], the albumin-bound fraction is approximately $95 \%$ [3]. The poor removal of PBUTs with conventional HD is evidenced by the fact that pre-dialysis levels of IS and pCS have been found to be as much as 116-fold and 41-fold higher, respectively, than in age-matched healthy controls, while pre-dialysis concentrations of non-protein-bound solutes with comparable molecular weight, such as urea and creatinine, were only 5- and 13 -fold higher, respectively [8]. Strong protein-binding results in a low reduction ratio of 20 to $35 \%$ for prototypical PBUTs [9], while the reduction ratio for small non-protein-bound solutes such as urea is around $80 \%$ during a conventional $4 \mathrm{~h}$ hemodialysis session [10]. The reduction ratio of a solute is a measure of dialysis session efficacy and indicates the percentage reduction in total serum concentration for this solute during a given dialysis duration. For PBUTs such as 3-carboxy-4-methyl-5propyl-2-furanpropionate (CMPF), very strong binding to albumin results in a negligible free fraction, such that their removal is practically zero. The reduction ratio for CMPF with conventional HD is often negative [3,11]. Note that the negative reduction ratio of CMPF does not suggest that there is an increase in CMPF generation rate due to dialysis; rather, it is an indication of the fact that protein concentration (and thus bound CMPF) is increased due to ultrafiltration.

To remove this class of toxin, we proposed a method where PBUTs can be removed by competitive binding, also known as the displacer method [12,13]. In the sections below, we will first describe the concept, followed by evidence ranging from bench to clinical studies. Subsequently, we summarize in silico evidence and comparisons of various extracorporeal modalities with respect to PBUT removal. We also highlight the potential application of this binding competition approach to treat drug intoxications. Finally, we provide a brief discussion of the other technologies that aim to improve PBUT removal and conclude with thoughts on the next steps to make this concept a clinical reality.

\section{Binding Competition for PBUT Removal}

Binding competition is a well-known and often-utilized process in pharmacology. Fundamentally, much of the occupancy-driven drug pharmacology acts on the premise of binding to a receptor/protein of interest. An administered drug molecule can work as a receptor agonist, antagonist, or inhibitor, while an endogenous ligand molecule may also be competing for the same binding site on the receptor. Binding competition studies are also critical for elucidating potential drug-drug interactions, especially in patients with complex medication regimen due to multiple comorbidities. In the proposed concept, we utilized the same binding competition method but introduce the binding competitor into the extracorporeal circuit where it competes for the same binding site as the PBUTs on the albumin molecule (Figure 1). This renders a larger fraction of the PBUTs unbound, which increases the diffusion gradient and improves dialytic removal.

While terms like "PBUT displacement" and "displacer-enhanced dialysis" are occasionally used to refer to the concept, those are technically misnomers. Rather than displacement [illustrated in Equation (1) below], the mechanism at play is competitive binding [illustrated in Equation (2) below]. PBUTs are reversibly bound to albumin with weak Van der Waals forces and are always in a dynamic equilibrium with the carrier protein. When an exogenous compound that binds to the albumin PBUT binding site is introduced, it results in a reduced free protein concentration, leading to a shift in dynamic equilibrium to provide more free protein, as per Le Chatelier's law of chemical equilibria [14] [see Equation (2)]. Thereby, in effect, more toxins also become free and thus dialyzable. These processes are amenable to quantitative analysis since protein-drug binding affinity data are available for most drug compounds [15].

$$
\begin{aligned}
& \text { Equation } 1:[\text { Protein }- \text { toxin }]+[\text { Drug }] \leftrightarrow[\text { Protein }- \text { Drug }]+[\text { Toxin }] \\
& \text { Equation } 2:[\text { Protein }- \text { toxin }] \leftrightarrow[\text { Protein }]+[\text { Toxin }]
\end{aligned}
$$




$$
[\text { Protein }- \text { Drug }] \leftrightarrow[\text { Protein }]+[\text { Drug }]
$$

Though simple, binding competition significantly improves PBUT removal, as highlighted in the sections below.

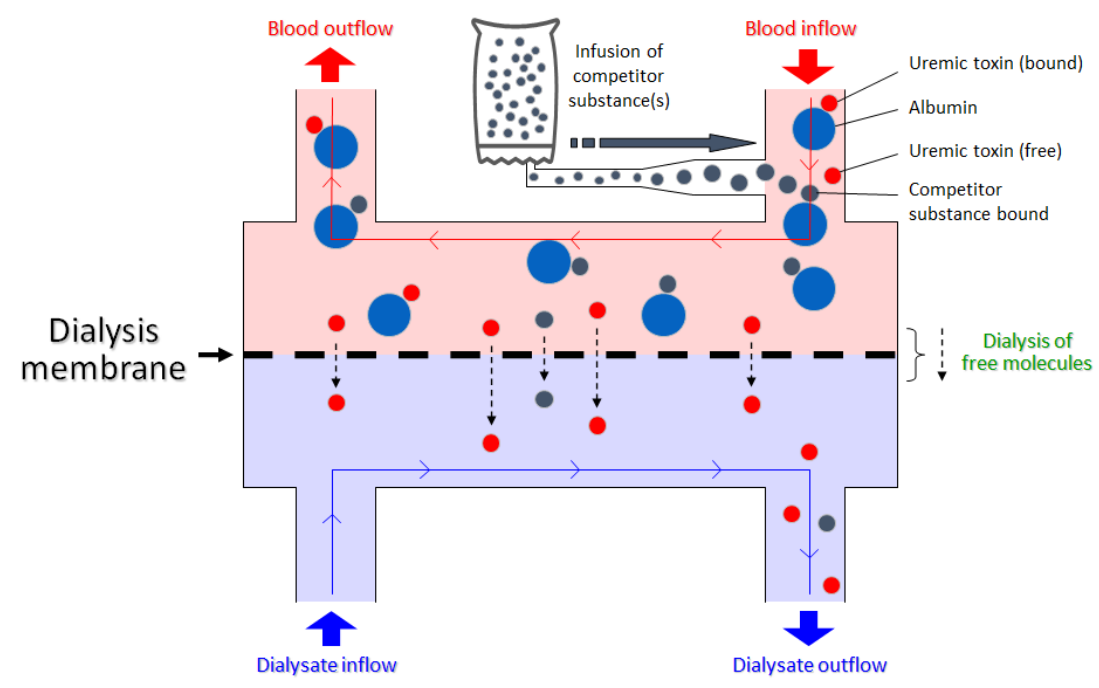

Figure 1. Schematic of binding competition between the protein-bound uremic toxin and competitor substance for the same binding site. The competitor drug is infused pre-dialyzer, leading to an increase in free toxin concentration and thus improved dialytic removal.

\section{Evidence from Bench Studies}

In 2015, Tao et al. were the first to test the binding competition concept for enhancing the dialytic removal of PBUTs [13]. They used tryptophan (TRP) and docosahexaenoic acid (DHA) as IS competitors and validated the concept by measuring IS concentration in the dialysate outlet stream. In their in vitro setup, $4 \%$ human serum albumin (HSA) solution spiked with IS was circulated through the dialyzer. The binding competitors (TRP or DHA), infused on the blood side of the circuit upstream of the dialyzer, competed for the IS binding site on albumin and led to an increase in IS concentration in the dialysate outlet stream. The fractional removal of IS was expressed as the amount per unit of time leaving the dialysate outlet as a percentage of the amount per unit of time entering at the blood inlet. When infusing phosphate buffer solution (PBS) without any added binding competitor, IS removal was $10.2 \%$, which improved to $18.5 \%$ with TRP and to $27.7 \%$ with DHA added to the infusion. Since the binding affinity of DHA to albumin $\left(1.0 \times 10^{7} \mathrm{M}^{-1}\right)$ is much higher than that of TRP to albumin $\left(1.0 \times 10^{4} \mathrm{M}^{-1}\right)$ [16], DHA is the stronger binding competitor of the two and leads to a larger improvement in dialytic removal of IS. Figure 2 shows a schematic of the bench setup used and summarizes the improvement in IS removal from baseline.

In 2016, Tao et al. further validated the binding competition approach ex vivo, where human whole blood spiked with IS, indole-3-acetic acid (IAA), and hippuric acid (HA) was dialyzed with either an ibuprofen + furosemide infusion or with a TRP infusion only, and toxin removal in the dialysate outlet stream was compared against phosphate-buffered saline infusion without binding competitors [17]. The ibuprofen and furosemide cocktail increased the IS fractional removal from $6.4 \%$ to $18.3 \%$, and IAA fractional removal from $16.8 \%$ to $34.5 \%$. TRP infusion increased the fractional removal of IS and IAA to $10.5 \%$ and $27.1 \%$, respectively. Moderate effects were observed for HA in all infusion scenarios (Figure 3). This study confirmed important aspects about the binding affinity of toxins as well as that of binding competitors. For PBUTs with weak binding affinity to albumin, binding competitors provided only moderate gains in terms of toxin removal. Conversely, competitors with stronger binding affinity provided greater improvement in PBUT removal; here, the ibuprofen binding affinity $\left(2.7 \times 10^{6} \mathrm{M}^{-1}\right)$ was much higher than the TRP binding 
affinity [16]. Tao et al. did not use DHA in this ex vivo setup because it caused hemolysis (data not shown).
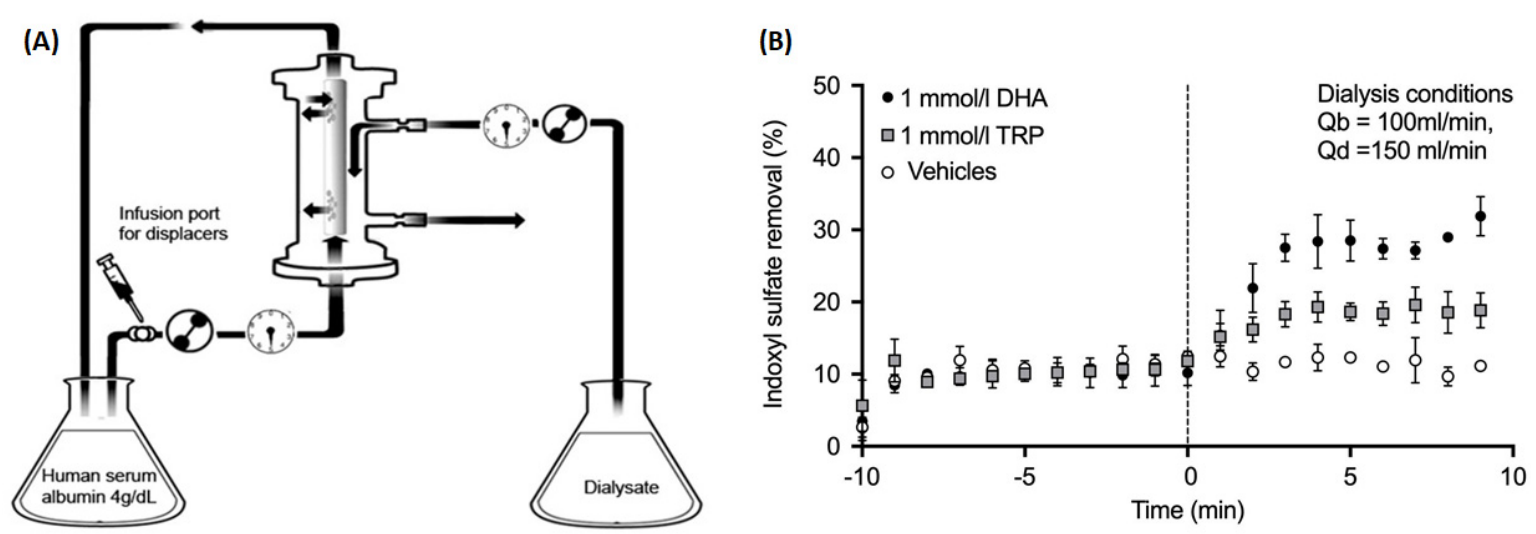

Figure 2. (A) In vitro dialysis setup where albumin solution spiked with indoxyl sulfate was dialyzed against standard dialysate solution. Two binding competitors (denoted as "displacers") were tested individually. (B) Indoxyl sulfate removal (measured at the dialysate outlet) for $10 \mathrm{~min}$ before and $10 \mathrm{~min}$ after starting the infusion upstream of the dialyzer (start of infusion denoted by the vertical dashed line). Three types of infusions were tested: phosphate-buffered saline (PBS) only ("Vehicle"), PBS with $1 \mathrm{mmol} / \mathrm{L}$ tryptophan ("TRP"), and PBS with $1 \mathrm{mmol} / \mathrm{L}$ docosahexaenoic acid ("DHA").

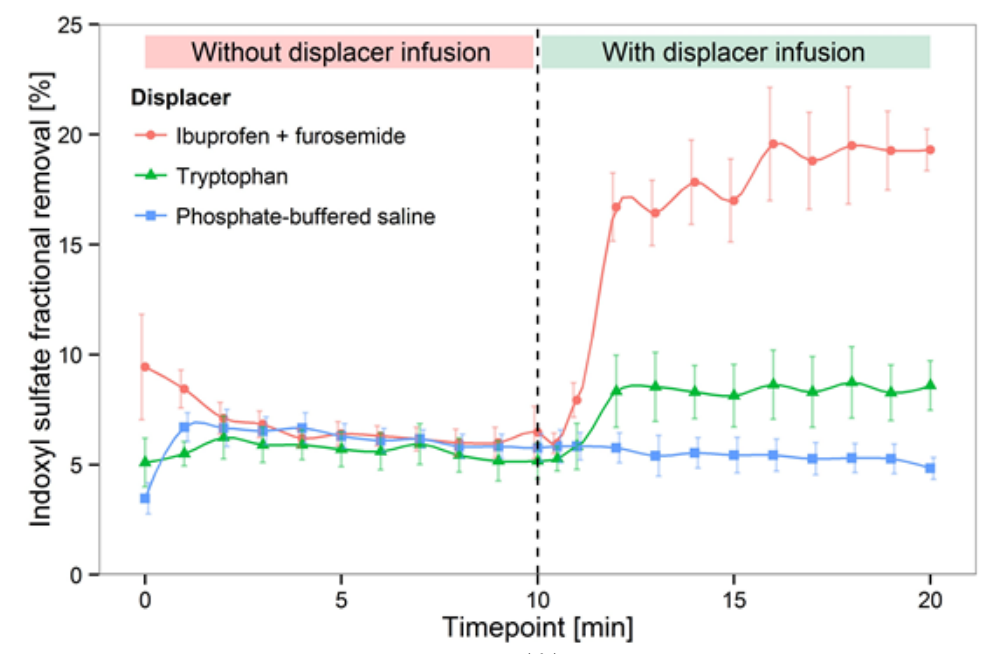

(A)

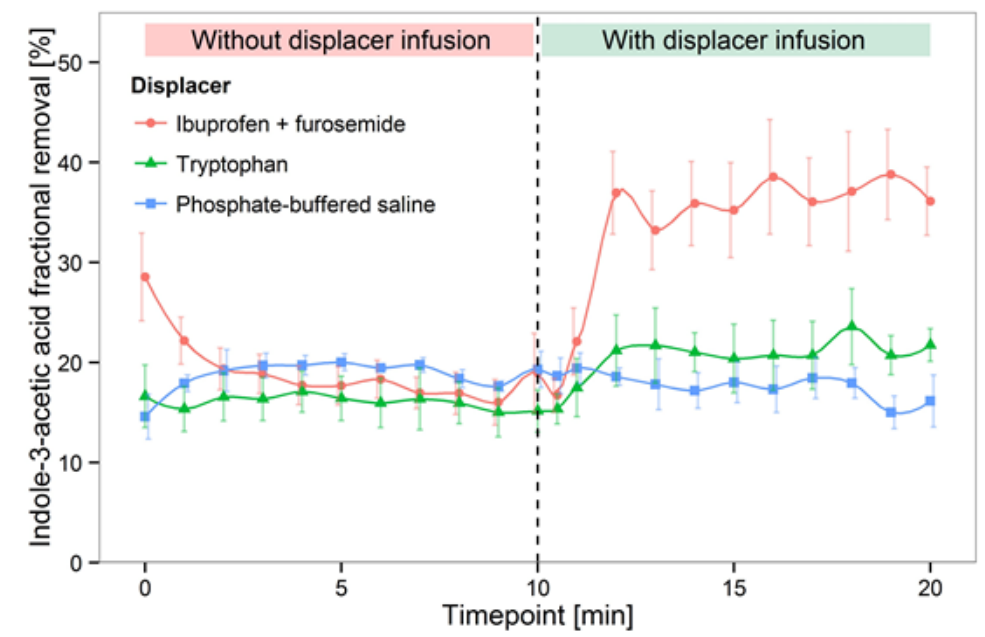

(B)

Figure 3. Cont. 


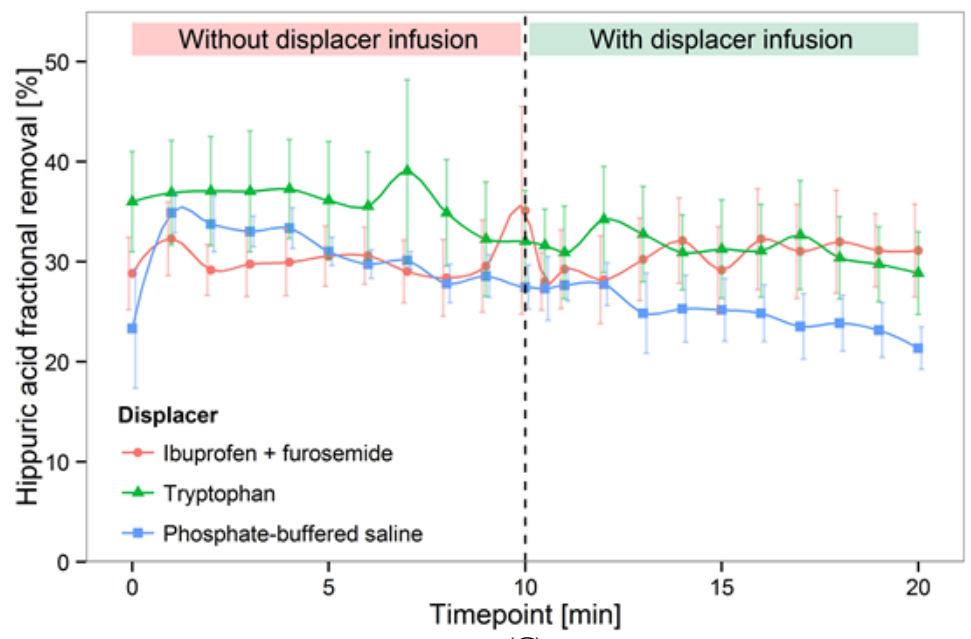

(C)

Figure 3. Binding competitor (denoted as "displacer") infusion in ex vivo setup improved fractional removal of (A) indoxyl sulfate, (B) indole-3-acetic acid, and (C) hippuric acid. In this bench setup, uremic blood was dialyzed conventionally for the first $10 \mathrm{~min}$, followed by infusion of a binding competitor for $10 \mathrm{~min}$.

\section{Evidence from Pre-Clinical Studies}

In 2019, Li et al. used chronic kidney disease rat models and salvianolic acid infusion during microdialysis [18]. Salvianolic acids are phytochemicals and strongly bind to albumin. They are believed to have anti-oxidative properties. In 5/6 nephrectomized Sprague-Dawley rats on microdialysis, Li et al. collected a dialysate sample every $30 \mathrm{~min}$ for $4 \mathrm{~h}$. The first $2 \mathrm{~h}$ of the experiment served as the control, while Danhong injection (DHI, mixture of salvianolic acids) was injected intravenously during the remaining $2 \mathrm{~h}$ of microdialysis. Comparing the infusion phase with the control, the IS and pCS removal improved by $135.6 \%$ and $272 \%$, respectively. The authors also used lithospermic acid only (one of the salvianolic acids), which improved IS and pCS removal, respectively, by $119.5 \%$ and $127.5 \%$ in comparison to control. Higher removal by Danhong injection in comparison to lithospermic acid may be due to the cumulative effect of the number of salvianolic acids present in DHI. This study highlights an important point regarding the use of a binding competitor cocktail that targets multiple binding sites on albumin molecules to exert an even larger removal of PBUTs during dialysis.

In 2019, Shi et al. also validated the binding competition method in in vitro experiments and pre-clinical uremic rat models [19]. They first tested the inhibitory effect of free fatty acids (FFAs) on the albumin-binding of CMPF, pCS, IS, and IAA in an in vitro setup, where human albumin solution spiked with PBUTs was dialyzed against standard bicarbonate buffer. Infusion of FFAs upstream of the dialyzer increased the fractional removal of pCS, IS, and IAA from $8.00 \%, 11.68 \%$, and $15.38 \%$, respectively, at baseline to $28.21 \%, 35.42 \%$, and $40.18 \%$. CMPF fractional removal increased to $14.4 \%$, with no removal at baseline. In the pre-clinical rat models, 16 weeks after $5 / 6$ nephrectomy, a control group with saline infusion was compared to a treatment group with intralipid emulsion (ILE) infusion. Intravenous infusion occurred $30 \mathrm{~min}$ before the start of dialysis and allowed serum non esterified free fatty acid levels to reach six times higher than the control when dialysis started and remained elevated for most of the experiments. Total solute removal, measured using total dialysate collection in $180 \mathrm{~min}$ of dialysis, improved up to $300 \%$ for PBUTs in the ILE infusion arm, whereas it remained unchanged for the non-protein-bound solutes urea and creatinine (Figure 4). 

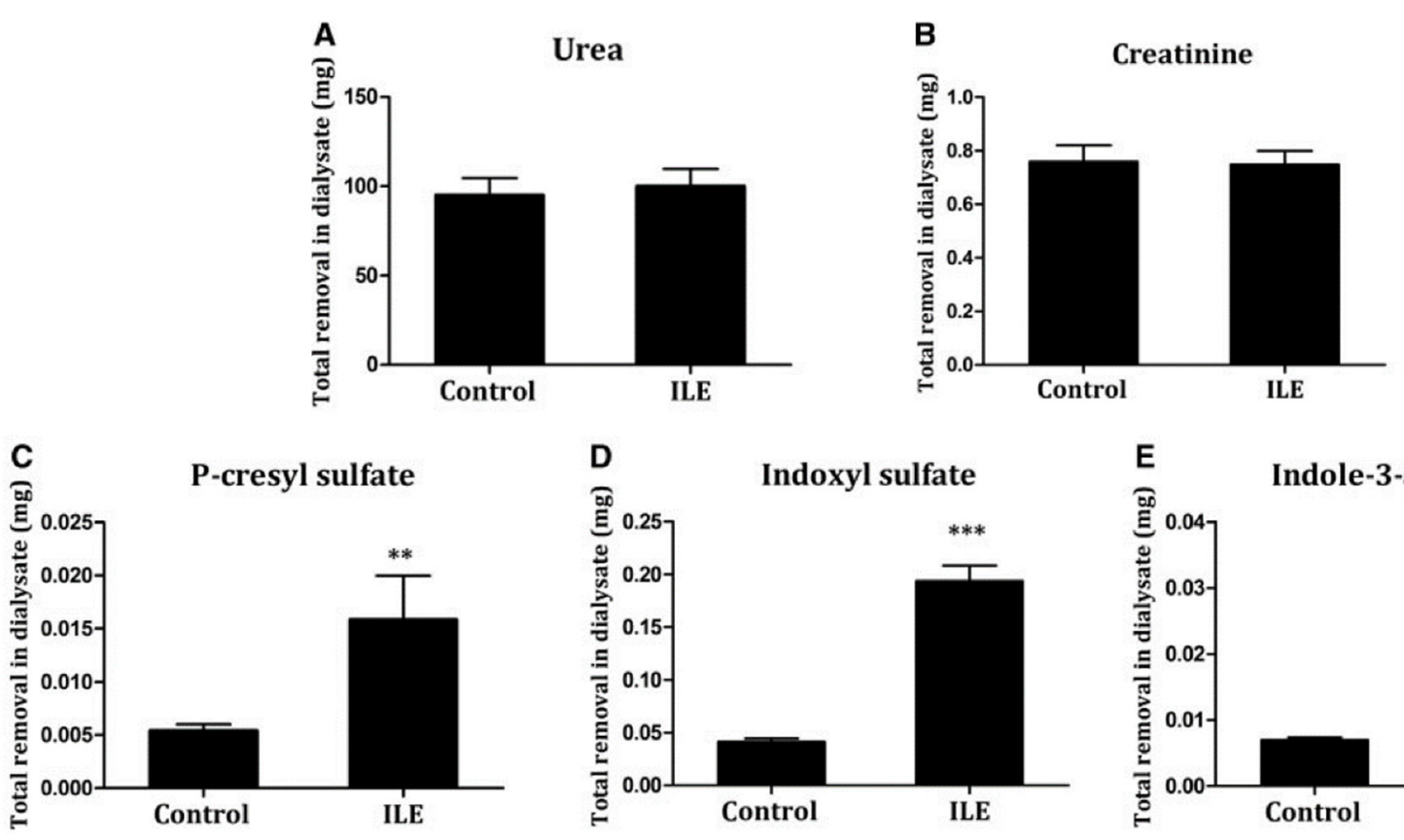

Figure 4. Total removal of (A) urea, (B) creatinine, (C) p-cresyl sulfate, (D) indoxyl sulfate, and (E) indole-3-acetic acid in $3 \mathrm{~h}$ dialysis in pre-clinical 5/6 nephrectomized rat model. Removal was studied in the control arm vs. intralipid emulsion infusion (binding competitor) arm (figure obtained with permission from NDT). ${ }^{* * *} p<0.001$ and ${ }^{* *} p<0.01$ compared with the control group.

In a further pre-clinical study comprising a uremic rat model, Shi et al. 2021 studied albumin dialysis and binding competition separately, as well as in combination. They used $4 \%$ bovine serum albumin in bicarbonate dialysate for albumin dialysis and $\omega-6$ soybean oilbased lipid emulsion as a binding competitor. Binding competition outperformed albumin dialysis and improved IS and pCS removal by approximately 10-fold in comparison to conventional $4 \mathrm{~h}$ HD. Notably, combining binding competition and albumin dialysis further improved the removal of putative PBUTs [20]. This study indirectly underscores the fact that protein binding is the primary resistance for PBUTs removal. Once this resistance is overcome by binding competition, combination therapies such as albumin dialysis or membrane adsorption with binding competition can significantly improve PBUTs removal. Note that the use of FFAs as binding competitors can not only improve PBUT removal but may also have salutary effects in dialysis patients with appropriate administration dosages.

\section{Clinical Evidence}

In 2019, Madero et al. were the first to study the effect of binding competition in a clinical proof-of-concept study with 18 patients [21]. In a 240 min conventional HD, they infused $800 \mathrm{mg}$ ibuprofen into the arterial line of the extracorporeal circuit, upstream of the dialyzer, from minutes 21 to 40 . They observed the dialysate clearances of IS, pCS, TRP, and non-protein bound solutes (Figure 5). Between the pre-infusion (0-20 min) and infusion periods (21-40 $\mathrm{min}$ ), dialysate clearance of IS and pCS increased from 6.6 to $20 \mathrm{~mL} / \mathrm{min}$ and 4.4 to $14.9 \mathrm{~mL} / \mathrm{min}$, respectively. TRP clearance increased moderately, while removal of urea and creatinine remained unchanged. 

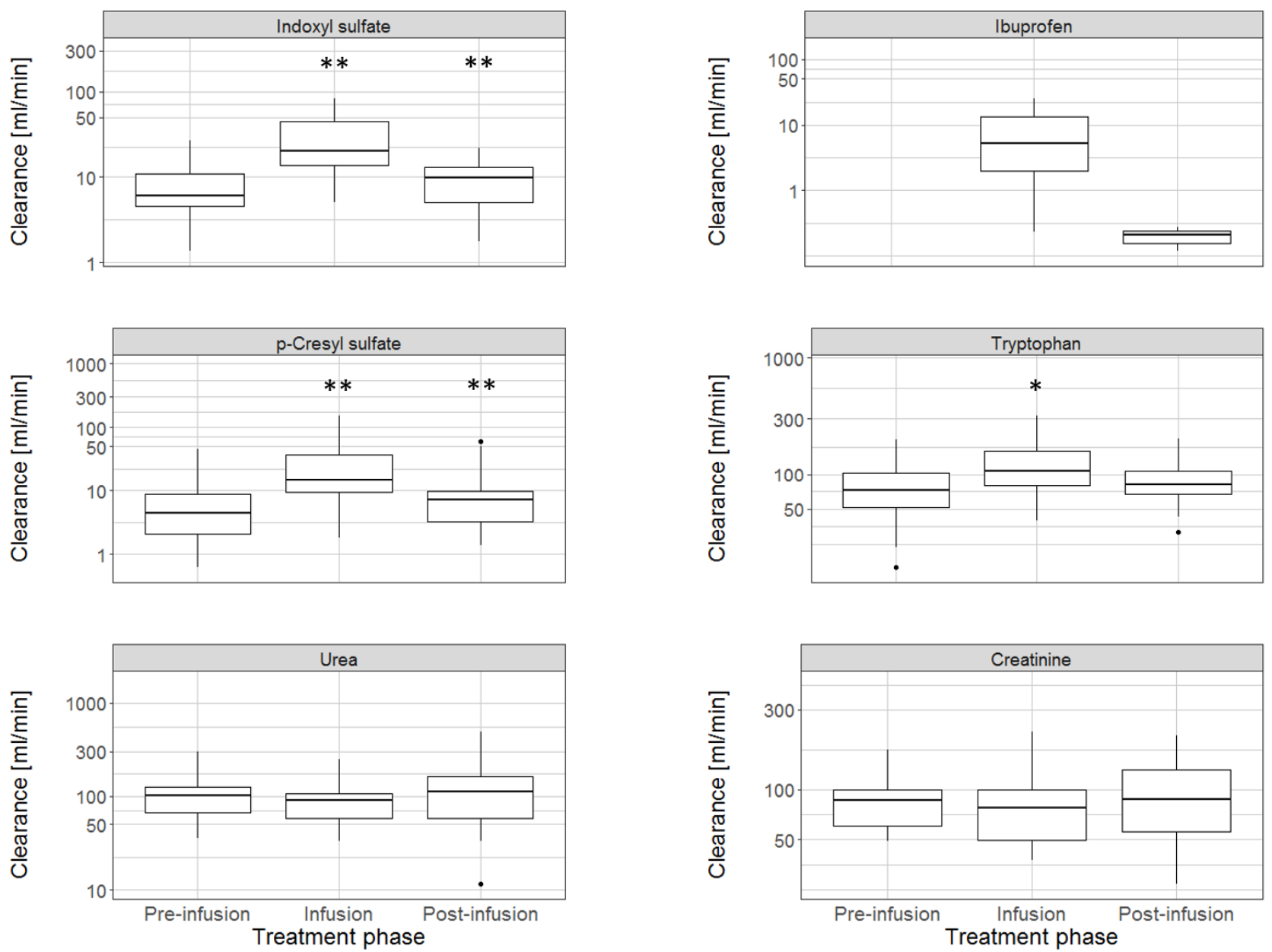

Figure 5. Dialytic clearance of uremic solutes during conventional hemodialysis before, during, and after infusion of a binding competitor into the arterial line upstream of the dialyzer. Ibuprofen was used as the binding competitor. Compared to the pre-infusion phase, there was a significant increase in indoxyl sulfate and p-cresyl sulfate clearance during the ibuprofen infusion, while the clearance of urea and creatinine (non-protein bound solutes) did not change. [* $p$-value, 0.01 compared with preceding phase; ${ }^{* *} p$-value, 0.001 compared with preceding phase; based on Wilcoxon signed rank test].

\section{In Silico Evidence}

To quantify total solute removal during a dialysis session and to study the long-term effect of binding competitor infusion during dialysis, we have developed a mathematical model that describes the intra- and inter-dialytic kinetics of PBUTs. The baseline model, without a binding competitor, was calibrated and validated using clinical data [15]. The model captures the dynamic equilibrium between PBUT and protein, as well as competitor drug and protein. In silico analysis informed us that competitive binding during HD significantly outperforms other state-of-the-art dialysis therapies, namely pre- and postdilution hemodiafiltration and ideal membrane adsorption (Figure 6) [22]. These in silico findings are qualitatively validated by Shi et al. 2021, who compared binding competition and adsorption (by albumin dialysis) in pre-clinical uremic rat models and observed that binding competition outperformed adsorption [20].

In Maheshwari et al., a binding competitor was infused in an arterial line at a constant rate during $4 \mathrm{~h}$ of simulated HD session. Adsorption was modeled such that any free toxin passing over to the dialysate side of the dialyzer membrane is completely adsorbed so that the toxin concentration on the dialysate side is always zero (analogous to an infinitely high dialysate flow rate). For a detailed description of the model and simulation setup, refer to the original article [22]. 

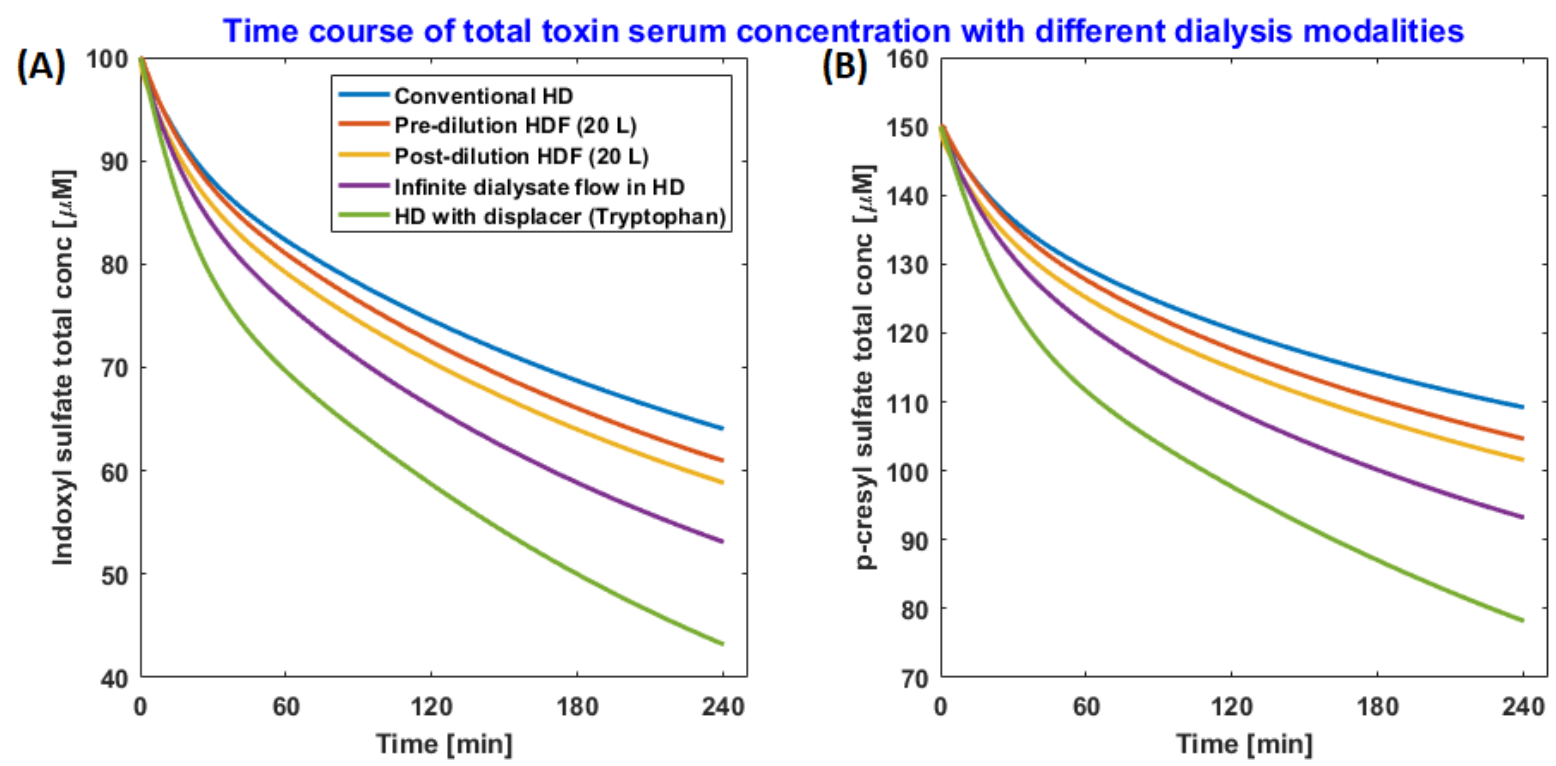

Figure 6. Time course of (A) total indoxyl sulfate (IS) and (B) p-cresyl sulfate (pCS) serum concentration with different extracorporeal dialysis modalities. The line color legend shown in the left panel applies to both plots.

Model simulations suggest that strong binding affinity is not the only criterion for the choice of a good binding competitor. For example, a higher amount of TRP (2000 mg in $500 \mathrm{~mL}$ saline) can outperform ibuprofen ( $800 \mathrm{mg}$ in $200 \mathrm{~mL}$ saline), even though tryptophan binding affinity to albumin is an order of magnitude lower than that of ibuprofen [16]. The ibuprofen dose was restricted to $800 \mathrm{mg}$ in our simulations as per FDA guidelines for a single-dose administration. Prolonged (one-month) use of TRP reduces the IS and pCS time-averaged concentration by $28.1 \%$ and $29.9 \%$, respectively, compared to conventional HD. In Figure 7, we highlight the long-term kinetics and time-averaged concentration of pCS with and without a binding competitor. Here, a typical HD subject $70 \mathrm{~kg}$ in weight was dialyzed 3 times a week $\times 4$ h per session, and the binding competitor was infused upstream of a dialyzer at a constant rate during dialysis [22].
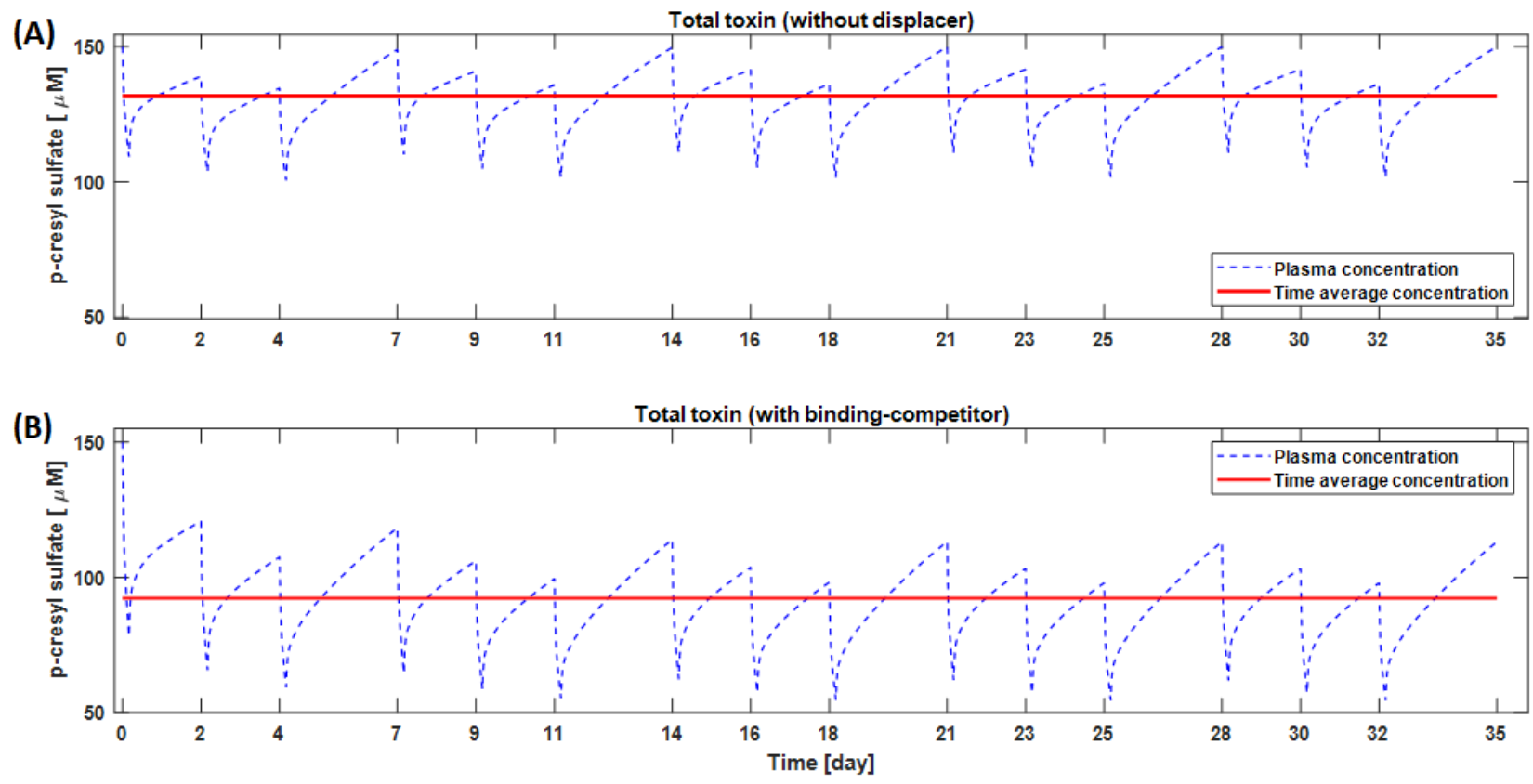

Figure 7. Monthly time-course of $\mathrm{p}$-cresyl sulfate $(\mathrm{pCS})$ concentration without $(\mathbf{A})$ and with binding competitor (B). The binding competitor tested in these simulations was $2000 \mathrm{mg}$ of tryptophan dissolved in $500 \mathrm{~mL}$ saline. 


\section{Treatment of Drug Intoxications}

In further in silico analyses, we explored the use of binding competition beyond PBUT removal to improve the treatment of intoxication with protein-bound drugs using HD [23]. Specifically, we tested ibuprofen to treat carbamazepine intoxication and aspirin to treat phenytoin intoxication. In both scenarios, we observed a significantly faster lowering of drug concentrations with the use of binding competitors vs. standard dialysis. Our model also provided insights into the effect of binding competitor half-life; specifically, that the use of binding competitors with longer plasma half-lives further reduced the treatment time required to lower the concentration of the offending drug. As per Extracorporeal Treatments in Poisoning (EXTRIP) working group guidelines, extracorporeal therapy is only recommended in cases of severe intoxications with phenytoin or carbamazepine because the free drug fraction in less severe intoxications is low for dialysis to be effective [24,25]; however, binding competitor-augmented HD can be a treatment option even in less severe cases and may also outperform adsorption-based hemoperfusion [22]. It remains to be explored whether these predicted results hold true in clinical settings. A summary of all evidence is reported in Table 1 in chronological order of publication date.

Our mathematical model [22] can be used in a number of ways, e.g., (1) as a potential tool for pre-screening the efficacy of various binding competitor candidates in order to select the most promising ones for subsequent clinical studies; (2) to personalize the dose of a competitor drug based on patient size, PBUT levels, prescribed ultrafiltration volume, etc.; (3) to test other extracorporeal modalities such as albumin dialysis, hemodiafiltration, and hemoperfusion; (4) to test the efficacy of a combination of binding competitors where the competitor molecules may target different binding sites on the albumin molecule (as in Li et al. 2019 [18]); (5) to optimize the intra-dialytic infusion profile for the binding competitor(s) to maximize toxin removal for a given amount of binding competitor used; or (6) to compare binding competitor infusion before the start of dialysis (as used in the rat study by Shi et al. [19]) with infusion during dialysis (as used in the clinical study by Madero et al. [21]). Regarding the timing of binding competitor infusion, we believe that infusion into the patient before dialysis may have detrimental effects due to a temporary increase in systemic free PBUT concentrations. Similarly, in the treatment of drug intoxication, infusing the binding competitors before dialysis may increase acute toxicity and lead to adverse outcomes. 
Table 1. Summary of existing evidence regarding use of binding competitor(s) for removal of protein-bound uremic toxins (PBUTs).

\begin{tabular}{|c|c|c|c|c|c|}
\hline Study Reference & Study Setting & PBUT(s) Studied & Binding Competitor(s) Used & Study Metric & Study Outcome \\
\hline Tao et al. 2015 [13] & In vitro & IS & $\begin{array}{l}\text { TRP or docosahexaenoic acid } \\
\text { (DHA) infused in extracorporeal } \\
\text { circuit at constant rate }\end{array}$ & $\begin{array}{l}\text { Fractional removal in } \\
\text { the dialysate }\end{array}$ & $\begin{array}{c}\text { TRP improved IS fractional removal } \\
\text { from } 10.2 \% \text { at baseline to } 18.5 \% \text {; } \\
\text { DHA improved the IS removal } \\
\text { to } 27.7 \%\end{array}$ \\
\hline Tao et al. 2016 [17] & Ex vivo & IS, IAA, HA & $\begin{array}{c}\text { Ibuprofen }+ \text { furosemide or TRP } \\
\text { infused in extracorporeal circuit at } \\
\text { constant rate }\end{array}$ & $\begin{array}{l}\text { Fractional removal in } \\
\text { the dialysate }\end{array}$ & $\begin{array}{l}\text { Ibuprofen + furosemide improved } \\
\text { IS removal from } 6.4 \% \text { to } 18.3 \% \text { and } \\
\text { IAA removal from } 16.8 \% \text { to } 34.5 \% \text {; } \\
\text { TRP improved IS and IAA removal } \\
\text { to } 10.5 \% \text { and } 27.1 \% \text {, respectively. }\end{array}$ \\
\hline Li et al. 2019 [18] & Pre-clinical uremic rat model & IS, pCS & $\begin{array}{l}\text { Danhong injection or lithospermic } \\
\text { acid infused intravenously at } \\
\text { constant rate during latter } 2 \mathrm{~h} \text { of } 4 \text {-h } \\
\text { microdialysis. }\end{array}$ & $\begin{array}{l}\text { Removal in first } 2 \mathrm{~h} \\
\text { (without infusion) vs. } \\
\text { latter } 2 \mathrm{~h} \text { (with infusion) }\end{array}$ & $\begin{array}{c}\text { IS and pCS removal in dialysate } \\
\text { improved by } 119.5 \% \text { and } 127.6 \% \text {, by } \\
\text { lithospermic acid, respectively, } \\
\text { which made up of } 88 \% \text { and } 47 \% \text {, } \\
\text { respectively, of the total } \\
\text { displacement effects of IS and pCS } \\
\text { introduced by Danhong injection. }\end{array}$ \\
\hline Maheshwari et al. 2019 [22] & $\begin{array}{l}\text { In silico analysis of IS and } \\
\text { pCS removal during HD }\end{array}$ & IS, pCS & $\begin{array}{l}\text { TRP or ibuprofen infused into the } \\
\text { extracorporeal circuit at constant } \\
\text { rate during 4-h HD }\end{array}$ & $\begin{array}{c}\text { Time-averaged } \\
\text { concentration (TAC) after } \\
1 \text { month }\end{array}$ & $\begin{array}{l}\text { TRP infusion in every HD session } \\
\text { reduced the TAC by } 28 \% \text { for IS and } \\
30 \% \text { for pCS. }\end{array}$ \\
\hline Shi et al. 2019 [19] & In vitro & CMPF, IAA, IS, pCS & $\begin{array}{l}\text { Free fatty acids infused in } \\
\text { extracorporeal circuit at } \\
\text { constant rate }\end{array}$ & $\begin{array}{l}\text { Fractional removal in } \\
\text { the dialysate }\end{array}$ & $\begin{array}{c}\text { CMPF fractional removal improved } \\
\text { to } 14.4 \% \text { vs. no removal at baseline; } \\
\text { pCS, IS, and IAA fractional removal } \\
\text { from } 8 \%, 11.7 \% \text {, and } 15.7 \% \text { at } \\
\text { baseline to } 28 \%, 35 \% \text {, and } \\
40 \% \text {, respectively. }\end{array}$ \\
\hline Shi et al. 2019 [19] & Pre-clinical uremic rat model & pCS, IS, IAA & $\begin{array}{c}\text { Intralipid }^{\mathrm{TM}}(20 \%) \text { infused } \\
\text { intravenously } 30 \mathrm{~min} \text { before start } \\
\text { of dialysis }\end{array}$ & $\begin{array}{l}\text { Total solute removal in } \\
\text { spent dialysate }\end{array}$ & $\begin{array}{l}\text { Removal of pCS, IS, and IAA } \\
\text { increased approximately } 300 \% \text {, } \\
\text { compared to control. }\end{array}$ \\
\hline
\end{tabular}


Table 1. Cont.

\begin{tabular}{|c|c|c|c|c|c|}
\hline Study Reference & Study Setting & PBUT(s) Studied & Binding Competitor(s) Used & Study Metric & Study Outcome \\
\hline Madero et al. 2019 [21] & $\begin{array}{l}\text { First-in-man proof-of-concept } \\
\text { study in } 18 \text { ESKD patients on } \\
\text { maintenance hemodialysis }\end{array}$ & IS, pCS, HA, TRP & $\begin{array}{l}\text { Ibuprofen infused at constant rate } \\
\text { during } 20-40 \mathrm{~min} \text { of } 4-\mathrm{h} \mathrm{HD}\end{array}$ & $\begin{array}{l}\text { Dialysate clearance } \\
\text { comparison during } \\
\text { pre-infusion phase }(0-20 \\
\text { min) vs. infusion phase } \\
\quad(21-40 \mathrm{~min})\end{array}$ & $\begin{array}{c}\text { Clearance improved from } \\
6.6 \mathrm{~mL} / \mathrm{min} \text { to } 20 \mathrm{~mL} / \mathrm{min} \text { for IS, } \\
\text { and } 4.4 \text { to } 14.9 \mathrm{~mL} / \mathrm{min} \text { for pCS; } \\
\text { TRP clearance increased moderately. } \\
\text { Urea and creatinine clearance } \\
\text { were unchanged. }\end{array}$ \\
\hline Maheshwari et al. 2020 [23] & $\begin{array}{l}\text { In silico analysis of drug } \\
\text { intoxication treatment }\end{array}$ & $\begin{array}{l}\text { Phenytoin, } \\
\text { Carbamazepine }\end{array}$ & $\begin{array}{l}\text { Infusion in extracorporeal circuit at } \\
\text { constant rate. For phenytoin, } \\
\text { aspirin was infused; for } \\
\text { carbamazepine, ibuprofen } \\
\text { was infused }\end{array}$ & $\begin{array}{l}\text { Time required to bring } \\
\text { patient back into } \\
\text { therapeutic } \\
\text { concentration range }\end{array}$ & $\begin{array}{l}\text { For phenytoin, constant aspirin } \\
\text { infusion reduced the HD time from } \\
460 \text { min to } 330 \mathrm{~min} \text {; for } \\
\text { carbamazepine, constant ibuprofen } \\
\text { infusion reduced the HD time from } \\
265 \mathrm{~min} 220 \mathrm{~min} \text {. }\end{array}$ \\
\hline Shi et al. 2021 [20] & Pre-clinical uremic rat model & IS, pCS, IAA, HA & $\begin{array}{l}\text { Intralipid }{ }^{\mathrm{TM}} \text { infused intravenously } \\
30 \text { min before start of dialysis; } \\
\text { albumin dialysis with bovine serum } \\
\text { albumin; Combination of binding } \\
\text { competition and albumin dialysis }\end{array}$ & $\begin{array}{l}\text { Total solute removal in } \\
\text { spent dialysate }\end{array}$ & $\begin{array}{l}\text { In the Intralipid }{ }^{\mathrm{TM}} \text { arm, } \\
\text { approximately 10-fold increase in IS } \\
\text { and pCS removal compared to } \\
\text { control arm. }\end{array}$ \\
\hline
\end{tabular}

CMPF: 3-carboxy-4-methyl-5-propyl-2-furanpropionic acid; ESKD: end stage kidney disease; HA: hippuric acid; IAA: indole-3-acetic acid; IS: indoxyl sulfate; pCS: p-cresyl sulfate; TRP: tryptophane. 


\section{Discussion and Conclusions}

Binding competition is a paradigm shift in extracorporeal renal replacement therapies. Research spanning from bench studies to first-in-man clinical studies suggest that binding competition during dialysis can significantly improve the removal of PBUTs. Computer simulations suggest that the reduction ratio of strongly bound PBUTs can be improved from $35 \%$ in conventional HD to $60 \%$ in binding competitor-augmented HD [22]. Note that removal depends on the choice [17] and infused amount [22] of binding competitor.

Other extracorporeal techniques to improve PBUT removal are also under development. Borrowing from kidney physiology, Jansen and co-workers impregnated the blood-side of hollow fibers with organic anion transporter-1 [26]. In in vitro studies, this novel bio-membrane significantly reduced PBUT levels; results from pre-clinical studies are to follow. Though effective, the development of such bioengineered kidney tubules is complex and may be cost prohibitive. A new class of medium cut-off (MCO) membranes may leak a significant amount of protein -in a crossover study, use of a MCO dialyzer resulted in a $0.45 \mathrm{~g} / \mathrm{dL}$ reduction in median albumin concentration in 3-month period [27]. Theoretically, this albumin loss can augment PBUT removal. Non-extracorporeal interventions to lower PBUTs level include dietary protein restriction, biotic supplements, or use of oral adsorbents such as AST-120. These techniques primarily focus on reduced production or reduced absorption of PBUTs in the gut [28].

Though effective and attractive, the binding competition approach raises some important questions, e.g., regarding the accumulation of binding competitors in kidney failure patients with long-term use. Another consideration is the risk-to-benefit ratio of chronic use of binding competitors. In other words., chronic ibuprofen use may accelerate the loss of residual renal function and may cause gastrointestinal bleeding [29]. Ideally, binding competitors with minimal side effects and, if possible, even salutary effects, would be chosen. Free fatty acids and tryptophan may be viable candidates. However, they compete only for one albumin binding site (the one where IS and pCS bind). To remove other PBUTs such as CMPF and HA, one or more additional binding competitors need to be infused. More research is required before the binding competition approach may be used in clinical practice. Such research should focus on the following: (1) the identification of ideal binding competitor candidates that target important PBUTs and have a favorable risk profile; (2) studying the short- and long-term effects associated with the use of these binding competitor(s) on pre-dialysis PBUT concentrations as well as on patient outcomes. Provided that such ideal binding competitors can be identified and demonstrated to have a net-positive effect, their application in routine HD would likely be technically simple and relatively inexpensive. In summary, binding competitor-enhanced dialysis holds promise for significantly improving PBUT removal compared to current extracorporeal renal replacement therapies. Furthermore, the application of binding competition holds promise for rendering $\mathrm{HD}$ a viable therapy option in the treatment of intoxications with highly protein-bound drugs.

Author Contributions: V.M. conceptualized and prepared first draft of the manuscript. X.T., S.T. and P.K. provided inputs. All authors have read and agreed to the published version of the manuscript.

Funding: No funding provided.

Institutional Review Board Statement: Not applicable.

Informed Consent Statement: Not applicable.

Data Availability Statement: All evidence presented in this manuscript exist in public domain.

Conflicts of Interest: S.T. holds performance shares in Fresenius Medical Care. P.K. holds stock options in Fresenius Medical Care; he also receives royalties from UpToDate. V.M. and X.T. declare no conflict of interest. Renal Research Institute is fully owned subsidiary of Fresenius Medical Care North America. 


$\begin{array}{ll}\text { Abbreviations } \\ \text { CMPF } & \text { 3-carboxy-4-methyl-5-propyl-2-furanpropionate } \\ \text { DHA } & \text { Docosahexaenoic acid } \\ \text { HA } & \text { Hippuric acid } \\ \text { HD } & \text { Hemodialysis } \\ \text { HSA } & \text { Human serum albumin } \\ \text { IAA } & \text { Indole-3-acetic acid } \\ \text { IS } & \text { Indoxyl sulfate } \\ \text { pCS } & \text { p-cresyl sulfate } \\ \text { TRP } & \text { Tryptophan }\end{array}$

\section{References}

1. Vanholder, R.; Schepers, E.; Pletinck, A.; Neirynck, N.; Glorieux, G. An Update on Protein-Bound Uremic Retention Solutes. J. Ren. Nutr. 2012, 22, 90-94. [CrossRef]

2. Rosner, M.; Reis, T.; Husain-Syed, F.; Vanholder, R.; Hutchison, C.; Stenvinkel, P.; Blankestijn, P.; Cozzolino, M.; Juillard, L.; Kashani, K.; et al. Classification of Uremic Toxins and Their Role in Kidney Failure. Clin. J. Am. Soc. Nephrol. 2021, 16, CJN.02660221. [CrossRef]

3. Niwa, T. Removal of Protein-Bound Uraemic Toxins by Haemodialysis. Blood Purif. 2013, 35, 20-25. [CrossRef]

4. Krieter, D.H.; Hackl, A.; Rodriguez, A.; Chenine, L.; Moragues, H.L.; Lemke, H.-D.; Wanner, C.; Canaud, B. Protein-bound uraemic toxin removal in haemodialysis and post-dilution haemodiafiltration. Nephrol. Dial. Transplant. 2009, 25, $212-218$. [CrossRef] [PubMed]

5. Van Gelder, M.K.; Middel, I.R.; Vernooij, R.W.M.; Bots, M.L.; Verhaar, M.C.; Masereeuw, R.; Grooteman, M.P.; Nubé, M.J.; Dorpel, M.A.V.D.; Blankestijn, P.J.; et al. Protein-Bound Uremic Toxins in Hemodialysis Patients Relate to Residual Kidney Function, Are Not Influenced by Convective Transport, and Do Not Relate to Outcome. Toxins 2020, 12, 234. [CrossRef]

6. Sirich, T.L.; Meyer, T.W.; Gondouin, B.; Brunet, P.; Niwa, T. Protein-Bound Molecules: A Large Family with a Bad Character. Semin. Nephrol. 2014, 34, 106-117. [CrossRef] [PubMed]

7. Liabeuf, S.; Villain, C.; Massy, Z.A. Protein-bound toxins: Has the Cinderella of uraemic toxins turned into a princess? Clin. Sci. 2016, 130, 2209-2216. [CrossRef]

8. Sirich, T.L.; Funk, B.A.; Plummer, N.S.; Hostetter, T.H.; Meyer, T.W. Prominent Accumulation in Hemodialysis Patients of Solutes Normally Cleared by Tubular Secretion. J. Am. Soc. Nephrol. 2013, 25, 615-622. [CrossRef] [PubMed]

9. Magnani, S.; Atti, M. Uremic Toxins and Blood Purification: A Review of Current Evidence and Future Perspectives. Toxins 2021, 13, 246. [CrossRef] [PubMed]

10. Kotanko, P.K.; Martin, K.; Chen, C.; Levin, N.W. Hemodialysis: Principles and techniques. In Comprehensive Clinical Nephrology; Feehally, J.F., Tonelli, M., Johnson, R.J., Eds.; Elsevier: Amsterdam, The Netherlands, 2019.

11. De Smet, R.; Dhondt, A.; Eloot, S.; Galli, F.; Waterloos, M.A.; Vanholder, R. Effect of the super-flux cellulose triacetate dialyser membrane on the removal of non-protein-bound and protein-bound uraemic solutes. Nephrol. Dial. Transplant. 2007, 22, 2006-2012. [CrossRef] [PubMed]

12. Kotanko, P.; Levin, N.W. Method of Removing Protein-Bound Deleterious Substances during Extracorporeal Renal Replacement Treatment. In World Intelectual Prperty Organization WO2010/045474; World Intelectual Prperty Organization: Geneva, Switzerland, 2012.

13. Tao, X.; Thijssen, S.; Levin, N.; Kotanko, P.; Handelman, G. Enhanced Indoxyl Sulfate Dialyzer Clearance with the Use of Binding Competitors. Blood Purif. 2015, 39, 323-330. [CrossRef]

14. Jenkins, H. Le Chatelier's principle. In Chemical Thermodynamics at a Glance; Blackwell Publishing: Hoboken, NJ, USA, 2008; pp. 160-163.

15. Maheshwari, V.; Thijssen, S.; Tao, X.; Fuertinger, D.; Kappel, F.; Kotanko, P. A novel mathematical model of protein-bound uremic toxin kinetics during hemodialysis. Sci. Rep. 2017, 7, 10371. [CrossRef]

16. Varshney, A.; Sen, P.; Ahmad, E.; Rehan, M.; Subbarao, N.; Khan, R.H. Ligand binding strategies of human serum albumin: How can the cargo be utilized? Chirality 2010, 22, 77-87. [CrossRef]

17. Tao, X.; Thijssen, S.; Kotanko, P.; Ho, C.-H.; Henrie, M.; Stroup, E.; Handelman, G. Improved dialytic removal of protein-bound uraemic toxins with use of albumin binding competitors: An in vitro human whole blood study. Sci. Rep. 2016, 6, 23389. [CrossRef]

18. Li, J.; Wang, Y.; Xu, X.; Cao, W.; Shen, Z.; Wang, N.; Leng, J.; Zou, N.; Shang, E.; Zhu, Z.; et al. Improved dialysis removal of protein-bound uremic toxins by salvianolic acids. Phytomedicine 2019, 57, 166-173. [CrossRef] [PubMed]

19. Shi, Y.; Zhang, Y.; Tian, H.; Wang, Y.; Shen, Y.; Zhu, Q.; Ding, F. Improved dialytic removal of protein-bound uremic toxins by intravenous lipid emulsion in chronic kidney disease rats. Nephrol. Dial. Transplant. 2019, 34, 1842-1852. [CrossRef]

20. Shi, Y.; Tian, H.; Wang, Y.; Shen, Y.; Zhu, Q.; Ding, F. Improved Dialysis Removal of Protein-Bound Uraemic Toxins with a Combined Displacement and Adsorption Technique. Blood Purif. 2021, 1-11. [CrossRef] 
21. Madero, M.; Cano, K.B.; Campos, I.; Tao, X.; Maheshwari, V.; Brown, J.; Cornejo, B.; Handelman, G.; Thijssen, S.; Kotanko, P. Removal of Protein-Bound Uremic Toxins during Hemodialysis Using a Binding Competitor. Clin. J. Am. Soc. Nephrol. 2019, 14, 394-402. [CrossRef] [PubMed]

22. Maheshwari, V.; Thijssen, S.; Tao, X.; Fuertinger, D.H.; Kappel, F.; Kotanko, P. In silico comparison of protein-bound uremic toxin removal by hemodialysis, hemodiafiltration, membrane adsorption, and binding competition. Sci. Rep. 2019, 9, 909. [CrossRef] [PubMed]

23. Maheshwari, V.; Hoffman, R.; Thijssen, S.; Tao, X.; Fuertinger, D.H.; Kotanko, P. A model-based analysis of phenytoin and carbamazepine toxicity treatment using binding-competition during hemodialysis. Sci. Rep. 2020, 10, 11294. [CrossRef] [PubMed]

24. Anseeuw, K.; Mowry, J.B.; Burdmann, E.; Ghannoum, M.; Hoffman, R.; Gosselin, S.; Lavergne, V.; Nolin, T.D. Extracorporeal Treatment in Phenytoin Poisoning: Systematic Review and Recommendations from the EXTRIP (Extracorporeal Treatments in Poisoning) Workgroup. Am. J. Kidney Dis. 2016, 67, 187-197. [CrossRef] [PubMed]

25. Ghannoum, M.; Yates, C.; Galvao, T.F.; Sowinski, K.M.; Vo, T.H.V.; Coogan, A.; Gosselin, S.; Lavergne, V.; Nolin, T.D.; Hoffman, R.S.; et al. Extracorporeal treatment for carbamazepine poisoning: Systematic review and recommendations from the EXTRIP workgroup. Clin. Toxicol. 2014, 52, 993-1004. [CrossRef] [PubMed]

26. Jansen, J.; Fedecostante, M.; Wilmer, M.J.; Peters, J.G.; Kreuser, U.M.; Broek, P.H.V.D.; Mensink, R.; Boltje, T.J.; Stamatialis, D.; Wetzels, J.F.; et al. Bioengineered kidney tubules efficiently excrete uremic toxins. Sci. Rep. 2016, 6, 26715. [CrossRef] [PubMed]

27. Cozzolino, M.; Magagnoli, L.; Ciceri, P.; Conte, F.; Galassi, A. Effects of a medium cut-off (Theranova ${ }^{\circledR}$ ) dialyser on haemodialysis patients: A prospective, cross-over study. Clin. Kidney J. 2021, 14, 382-389. [CrossRef]

28. Takkavatakarn, K.; Wuttiputinun, T.; Phannajit, J.; Praditpornsilpa, K.; Eiam-Ong, S.; Susantitaphong, P. Protein-bound uremic toxin lowering strategies in chronic kidney disease: A systematic review and meta-analysis. J. Nephrol. 2021, 1-13. [CrossRef]

29. Jankovic, S.M.; Aleksic, J.; Rakovic, S.; Aleksic, A.; Stevanovic, I.; Stefanovic-Stoimenov, N.; Radosavljevic, M.; Kostic, M.; Tesic, D.; Petrovic, B. Nonsteroidal antiinflammatory drugs and risk of gastrointestinal bleeding among patients on hemodialysis. J. Nephrol. 2009, 22, 502. 